\title{
Electronic health (e-Health): a conceptual framework for its implementation in health services facilities
}

\author{
Christian Díaz de León-Castañeda*
}

Consejo Nacional de Ciencia y Tecnología (CONACYT), Centro de Investigación e Innovación en Tecnologías de la Información y Comunicación (INFOTEC), Aguascalientes, Aguascalientes, Mexico

\begin{abstract}
Electronic health (e-Health) is a broad concept that involves the application of Information and Communication Technologies (ICT) to systems for health surveillance, prevention, promotion and care. e-Health components mainly include supply and resource management systems (appointment schedules, clinical laboratory or pharmacy), electronic medical records, electronic prescription, clinical decision support systems, use of mobile devices, imaging systems, remote care systems, as well as teaching through digital media. Other components that can be regarded as part of e-Health are the massive data storage and analysis systems, artificial learning, as well as "internet of things" systems. In this work, a conceptual framework is proposed in order to analyze the implementation in e-Health components and their effects on the quality of health services provision.
\end{abstract}

KEY WORDS: Information Science. Quality management. Healthcare provision. Human resources in health.

\section{Introduction}

Public health has two major fields of study: population health conditions and health systems as an "organized social response" to these conditions. ${ }^{1}$ In this regard, a continuous approach to opportunities that enable improving the development of processes and optimize the use of resources in their different basic functions (stewardship, funding, generation of resources and provision of services) is necessary for health systems. ${ }^{2,3}$ In particular, in the function of health services provision, continuous improvement of the quality of processes (preventive, health promotion, curative and rehabilitative) is necessary. 4,5

The quality of health services provision has been defined as "the degree of adjustment between the characteristics of service supply and users or patients' expectations". Conceptually, two large dimensions are recognized for the assessment of health care quality: technical and interpersonal. The technical dimension is "the application of science and medical technologies in such a way that they yield maximum health benefits without increase their risks", whereas the interpersonal dimension is "adherence to socially defined values and standards that govern the interaction of individuals" and "ethical dictates of health-related professions". ${ }^{6}$ Donabedian identified three major approaches to the analysis or evaluation of health care quality: structure, process and outcome, where structural characteristics are determinants of quality in the development of the process activities and, in turn, these determine health outcomes. ${ }^{6}$ Moreover, several dimensions have been identified that integrally compose quality in the provision of health services: accessibility, equity, effectiveness, efficiency, safety and satisfaction. ${ }^{4,5,7-10}$
Correspondence:

${ }^{*}$ Christian Díaz de León-Castañeda

E-mail: cddeleon@conacyt.mx
Gac Med Mex. 2019;155:161-168

Contents available at PubMed www.gacetamedicademexico.com 
Information and communication technologies (ICT) constitute an opportunity to improve the variety of processes related to health. The vast field of ICT applications in the field of health is known as electronic health ("e-Health"), defined by the World Health Organization"11 as "the cost-effective and secure use of information and communication technologies (ICT) in support of health and health-related fields, including health-care services, health surveillance, health literature, and health education, knowledge and research"; however, the e-Health concept is still the subject of debate and currently there are different conceptualizations. 12-14

e-Health comprises a broad group of applications (e-Health components) that have the function to operate in an integrated manner and can be part of various public health and health systems fields of domain (e.g., epidemiological surveillance, prevention, promotion and health-care in general). Some studies have highlighted the effectiveness and efficiency (cost-effectiveness) of some e-Health components..$^{15-18}$ In view of this evidence, the World Health Organization and other institutions -such as the Pan American Health Organization, the Economic Commission for Latin America and the Caribbean and the Organization for Economic Cooperation and Development- have issued policies aimed at promoting ICT implementation..$^{19,20}$ However, problems persist for the access, implementation and operation of these components, mainly in developing countries, which generates digital divides at the micro (between people), meso (between institutions or health organizations) and macro levels (between geographical regions or countries). ${ }^{21,22}$

In this sense, several studies have highlighted the need to strengthen e-Health policies, as well as the need for better implementation systems for its various components in health services, in order for social and operational contexts to be considered. ${ }^{23-25}$ In the field of health technology, implementation science is a conceptual and instrumental tool that favors the study of factors that allow optimizing the adoption and appropriation of scientific evidence-based (cost-effective) health technologies. ${ }^{26,27}$ In this regard, several analytical frameworks have been developed. ${ }^{28,29}$

This work presents basic concepts of the various components of e-Health and a brief section on the process for its adoption-appropriation in the general population and in health personnel. These bases are used to present a proposal of a conceptual framework about e-Health components implementation and their effect on quality in health services provision.

\section{e-Health components}

In the provision of health services, ICT constitute important resources for the comprehensive integration of health information systems (HIS) ${ }^{*}$ at their different levels of application (population-based or health service-based). Through these systems, communication between health professionals, between health professionals and patients, as well as between patients has been favored. Likewise, ICT have penetrated into health systems (e.g., computer systems, landline and mobile phones or, more currently, Internet-based communication systems such as e-mail, social networks, specialized websites, etc.), which implies new processes of health prevention, promotion and care.

ICT have enabled better information storage and management systems through the digitalization of documentation involved in administrative processes such as user or patient information, resources (financial, material and human) and health supplies in general (drugs, medical devices, etc.). Specifically, service administration systems stand out, such as the appointment calendar for health services (electronic appointments to medical, dental, psychology, etc. services), as well as those involved with the clinical laboratory and pharmacy, among others. In addition, health care processes have evolved towards documentation digitalization, medical records on paper have become electronic medical records (EMR), ${ }^{32}$ medical prescriptions on paper have become electronic prescriptions, as well as the results of clinical, imaging or radiology studies are shifting from being delivered and analyzed in physical means to being processed by digital means (Picture Archiving and Commnunication Systems [PACS]). ${ }^{33}$

ICT evolution has allowed the development of remote care systems through electronic means, from the use of telephone-based technology to Internet-based systems, which integrates a wide array of systems that are comprised within the concept of telehealth, which implies the remote provision of preventive, health promotion or curative services. A broad field within telehealth is telemedicine and its various healthcare specialties (e.g., teleradiology, telepsychiatry, telerehabilitation, telesurgery, telecardiology, etc.). This technology stands out for its potential to favor access to specialized health

The World Health Organization has defined HIS as"interrelated component parts for acquiring and analyzing data and providing information (management information; health statistics; health literature) for the management of a health programme or system and for monitoring health activities". ${ }^{31}$ 
services for people in remote places (e.g., rural communities, indigenous or distant populations). ${ }^{34-36}$

The evolution of mobile communication technologies such as smartphones and portable devices (wearables such as bracelets, watches or other accessories) allows the monitoring of activities (physical exercise) or health conditions for people and the monitoring of these conditions and lifestyles by health professionals for decision-making purposes. These devices are increasingly being applied in various fields and make up the so-called "mobile health" ("m-Health"). ${ }^{* *}$ From a public health perspective, these devices represent opportunities for intervention in the general population for health promotion or collection of information related to population habits, behaviors or lifestyles, which constitutes an opportunity for the issuance of possible health risk alerts that can generate timely interventions (for epidemiological surveillance systems). ${ }^{37,38}$

As part of e-Health, clinical decision support systems (CDSS) should also be highlighted, which are auxiliary tools that can be resorted mainly by health professionals to make decisions during health care, which implies a potential impact on patient safety. These systems have been arbitrarily defined as "active knowledge systems that use two or more patient data items to generate case-specific advice", ${ }^{39}$ or as "software that is designed as an aid in clinical decision-making where the characteristics of an individual patient are combined with a computed clinical knowledge basis, and then patient-specific assessments or recommendations are presented to the clinical staff and/or to the patient for a decision", ${ }^{40}$ although some debate has arisen and the concept of "decision tool", which encompasses other support systems, has been widely suggested. ${ }^{41}$

There is a wide diversity of CDSS operation typologies, which depends on the contexts and the degree of implementation and development of ICT systems in health services. A taxonomy has been proposed for these systems based on five categories: the context of use, knowledge and data resources, type of clinical decision support, type of information delivery and work flow or system operation. ${ }^{42}$ This field

** Mobile health or m-Health is part of e-Health and has been defined by the e-Health Global Observatory (from the World Health Organization) as "medical and public health practice supported by mobile devices such as mobile phones, devices for patient monitoring, personal digital assistants (PDA) and other wireless devices". In addition, the different communication technologies involved were identified (SMS, GPRS, 3G, $4 \mathrm{G}$, GPS, Bluetooth). ${ }^{37}$ includes algorithm-based software or calculators for decision making (e.g., renal clearance calculations or scales for assessing patients' health status), as well as specialized software that automatically identifies errors during prescription according to patient characteristics.

Another important field of e-Health is the use of electronic means or websites for health education of health professionals, service users and the general population ("e-learning"), in order to promote good practice habits during health care (health personnel), as well as for the promotion of health or healthy habits (population). Furthermore, the use of websites is an opportunity to provide patients with access to information about their own health, thus empowering them to participate in decisions, or to promote communication with other patients (together with social networks) and this way generate support networks, which can be important in some chronic conditions (these activities have been associated with the term "e-patient"). ${ }^{43 * *}$

As other ICT applications in the area of health that are under development (or in use in some countries or specific health systems), the following could be mentioned:

- Management of the storage, analysis and use of large volumes of data big data for public health, epidemiological surveillance and health promotion purposes, as well as improvement of quality in the provision of services. ${ }^{45}$

- Application of "Internet of things" (IoT) systems in order to monitor the health and activities of patients (either inpatients or outpatients, through devices and sensors connected to Internet networks), as well as to control their treatment (e.g., dosage of their medications). ${ }^{46.47}$

- Computational learning systems ("machine learning"), with the purpose to promote automation of care processes and services, in order to generate the capacity to help in clinical decision-making for diagnosis or treatment of medical conditions. ${ }^{48,49}$

- Use of virtual or augmented reality technologies for educational, preventive or therapeutic purposes..$^{50}$

- Development of bioinformatics and its application in medicine (biomedical informatics). ${ }^{51 \dagger}$

- Continuous development of portable analytical systems (clinical analysis devices or sensors) coupled to mobile computer systems. ${ }^{52}$

**** Attributed to Ferguson, ${ }^{44}$ the term "e-patient" is defined as "individuals who are equipped, enabled, empowered and engaged in their health and health care decisions".

$\dagger$ Biomedical informatics refers to the use of patient genetic information for clinical decision making. It emerges as a new and interesting field related to genomic medicine. ${ }^{51}$ 
It should be noted that the different components of e-Health offer the possibility to be combined and interrelated (interoperability), thus generating a range of possibilities that comprehensively represent opportunities to strengthen health service provision systems. ${ }^{53,54}$

\section{Adoption-appropriation of e-Health components}

There are various ways by means of which society can adopt and appropriate ${ }^{\ddagger}$ ICT for health purposes, with two main types of stakeholders being identified: the general population (including health service users) and health service providers (either professionals or technicians).

\section{General population and health service users}

Involuntarily, the population can receive information on health prevention or promotion through mass media such as television, radio, cell phone SMS or Internet in its different modalities. In addition, the general population can voluntarily "adopt" some e-Health components, for example, seek health information or guidance through the use of means such as the telephone (phone consultation) or the Internet. This requires that people overcome the barriers (economic or sociocultural) to access to these technologies, making the decision to adopt these technologies and acquire the necessary digital skills for their use.

In the adoption-appropriation of these technologies by the population, various intrinsic and extrinsic factors can have influence. Among the intrinsic factors, age, gender, occupation, level of education, socioeconomic stratum and health conditions of people might play a role; while extrinsic factors that may influence include the social circles the individual belongs to, ICT implementation at the workplace, as well as in health institutions or services where care is received and the influence of the health personnel therein working. Several theoretical-conceptual frameworks have been developed for the study and analysis of these processes. ${ }^{5-57}$

$\ddagger$ The term adoption refers to the act of deciding to use the technologies (whether this decision is made by individuals or organizations). The term appropriation can have many connotations, levels and dimensions of analysis, at the individual level it refers to a level of "mastery" in the incorporation of technology in everyday and work activities. ${ }^{55,56}$ In the health professional sphere, the term adoption is more widely used.

\section{Health-care providers}

The adoption and use of some e-Health components are exclusive for health personnel; for example, EMR, electronic prescription systems, PACS, some CDSS, telehealth systems by the service providing party, etc.

As mentioned for the general population, in the process of adoption-appropriation of these components by health personnel, intrinsic factors such as age, gender, training and the field of health care they work in come into play, as well as extrinsic factors such as the practices adopted in the professional circle and implementation of these components in the health institutions or departments where they work. In this sense, in order for health personnel to adopt these technologies, the health organizations they work in need to overcome access barriers and promote an adequate implementation of these technologies in their personnel through the development of digital skills or competences. It should be noted that some components can be voluntarily and autonomously adopted by health personnel, such as apps for smartphones or specialized websites that facilitate different tasks involved in health care. Some theoretical-conceptual models have been developed to explain the use of and satisfaction with these technologies in the organizational context. ${ }^{26-29,55-59}$

\section{Conceptual framework proposal}

A framework has been proposed for the study of e-Health components implementation and their effect on the quality in health services provision integrating several analysis dimensions identified by Donabedian and other conceptual reviews (Figure 1). This conceptual framework involves two main components that are reviewed below.

\section{e-Health components implementation}

Health technologies implementation refers to the act of introducing these technologies in the structure or processes that are carried out in health services provision systems. In particular, implementation science promotes the use of technologies that have shown to

$\ddagger \ddagger$ In the field of e-Health, the generation of sound scientific evidence is important in order to avoid making the mistake of adopting technologies with little or no evidence. Moreover, the generation of regulatory frameworks that promote this aspect, as well as the use and operation of e-Health components in general, is also important. 


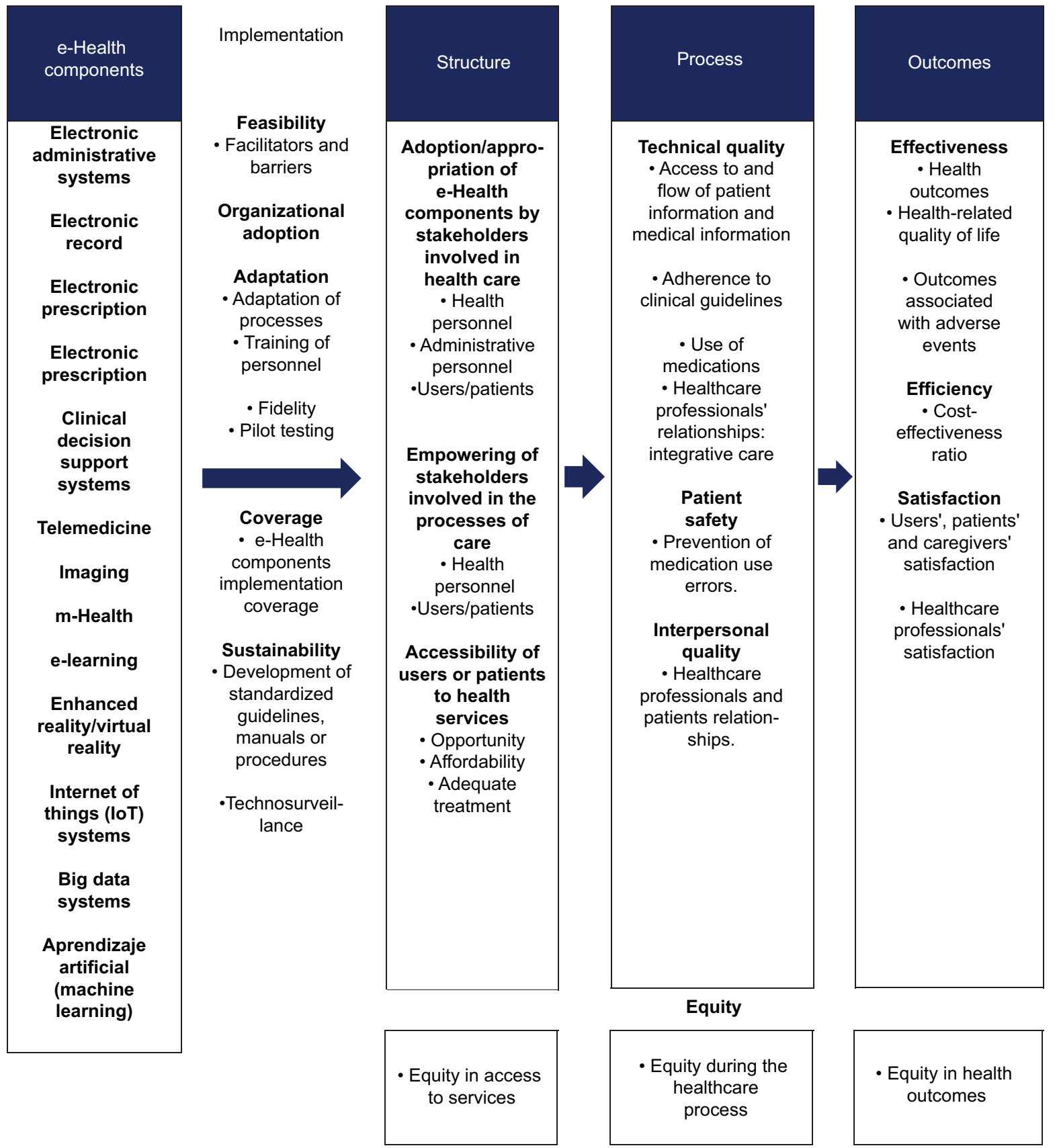

Figure 1. Conceptual framework for the analysis of e-Health components implementation and their effect on the quality of health services provision (own creation).

be effective, efficient and safe (based on evidence) $)^{\ddagger \neq}$ in the operational practice of health services. ${ }^{26,27}$ Different analytical frameworks and recommendations for the performance of implementation studies have been published. ${ }^{28,29,60,61}$

The first step to introduce e-Health components in health services implies a feasibility analysis process, which analyzes the facilitators and barriers to implementation (infrastructure, social or cultural factors). This process should be based on specialized studies that assess the need for technology implementation at the proposed place or department, so that equity in the access to the intervention or technology to be implemented is promoted. The next step is "organizational adoption", which involves the decision by the organization to implement the technology in its processes. This decision can be influenced by external and internal policies.

The third implementation step is "adaptation", which implies adjusting the organization's internal 
processes (in this case, health care processes), as well as the training of people (technical or administrative staff and service users) towards the introduction of technologies in these processes by promoting the acquisition of the necessary digital skills. During this adaptation process, it is necessary for "pilot tests" to be carried out in order to analyze the processes' operation. An important evaluation or study is "fidelity" assessment, which refers to the study of the degree at which an intervention was implemented as planned in a specific implementation plan or protocol (while adaptation evaluation refers to the degree at which the strategy or intervention is modified by users or people during implementation, to adjust to particular needs). ${ }^{26,60}$

The study of technological adoption-appropriation by the stakeholders involved in healthcare processes implies investigation of their technologies use and satisfaction with them.

"Sustainability" studies assess the degree at which an intervention or technology is maintained or "institutionalized" in a particular organization or department. ${ }^{26}$ As part of this aspect, the development of standard operating procedures for the purpose to standardize or normalize the processes based on the changes implied by the introduction of ICT could be included. In this point, it should be noted that the development of standard operating procedures or special procedures is necessary in order to monitor the performance of technologies by promoting technosurveillance systems.

Finally, "coverage" is the assessment of the fraction of the population that benefits from the implementation of technology in relation to the eligible population. ${ }^{26}$

\section{Analysis of effects on quality in health services provision}

e-Health components implementation in health services generates an effect or impact on the quality of health service provision at different levels:

a) Effects on structure. First, e-Health components implementation in health services will improve ICT technological infrastructure and its different modalities, such as networks, telecommunications, hardware and software. In addition, ICT adoption and access to information promotes the empowerment of the stakeholders involved in the care processes (both among health personnel and in users or patients). Furthermore, some e-Health components have the capacity to promote accessibility to services, ${ }^{9,10}$ such as electronic appointments and websites for patients, in addition to telehealth or telemedicine systems.

b) Effects processes. This approach includes the technical quality, interpersonal quality and patient safety dimensions. In the technical quality dimension, some e-Health components could promote the access to users' or patients' information systems (or to medical information in general), adherence to clinical guidelines, rational use of medications and patient compliance. Likewise some e-Health components might promote patient safety, especially CDSS (surveillance systems for adherence to guidelines or clinical standards), which would constitute a barrier that could prevent errors in the use of health technologies (such as medication error) reaching the patient. On the other hand, ICT could promote communication between health personnel which might help collaborative and inter-professional work (comprehensive care, considered an important attribute in the processes of health service provision. Furthermore, ICT might promote communication between health personnel and patients or patient adherence to medical appointments or treatments (electronic reminder systems). As part of interpersonal quality, some e-Health components could favor it by improving communication between health personnel and users or patients; however, there is also the risk that e-Health components implementation represents a barrier to communication between health personnel and patients, particularly during medical appointments and in contexts of work overload.

c) Effects on outcomes The effectiveness, efficiency and satisfaction dimensions are included. Given that effectiveness is a direct consequence of the processes or activities that are carried out in the approaching process, e-Health components have the potential to impact on people's health outcomes, as well as on their quality of life, or to promote a better use of health technologies, which would generate better results associated with their use (e.g., prevention of adverse events associated with medication errors). Furthermore, possible savings in the use of resources during health-care would imply an impact on the efficiency dimension. In addition, interpersonal 
quality during health-care processes, in addition to patients' health outcomes or self-perception on their own health, could have an impact on their satisfaction.

d) Equity. e-Health components represent an opportunity to promote health equity at the structure, process and outcome levels. However, equity in ICT implementation needs to be promoted in this area, in order for e-Health components not to appear as one more element of health inequality or inequity (digital divide in health-care).

\section{Conclusions}

ICT are a valuable and comprehensive tool for the provision of health services that require continuous assessment of their implementation and impact on quality, and the proposed conceptual framework could therefore be an approach in this area.

\section{References}

1. Frenk J. La salud de la población, hacia una nueva salud pública. México: Fondo de Cultura Económica; 1994.

2. Murray C, Frenk J. A framework for assessing the performance of health systems. Bull World Health Organ. 2000;78:717-731.

3. World Health Organization. The world health report 2000. Health systems: improving performance. Ginebra, Suiza: World Health Organization; 2000.

4. World Health Organization. Quality of care. A process for making strategic choices in health systems. Ginebra, Suiza: World Health Organization; 2006.

5. Institute of Medicine, Committee on Quality of Health Care in America Crossing the quality chasm: a new health system for the $21^{\text {st }}$ century. BJM. 2001;323:1192

6. Donabedian A. La calidad de la atención médica, definición y métodos de evaluación. México: La Prensa Médica Mexicana; 1984

7. Arah OA, Westert GP, Hurst J, Klazinga NS. A conceptual framework for the OECD Health Care Quality Indicators Project. Int J Qual Health Care. 2006;18:5-13.

8. Campbell SM, Roland MO, Buetow SA. Defining quality of care. Soc Sci Med. 2000;51:1611-1625

9. Frenk J. El concepto y la medición de accesibilidad. Salud Publica Mex. 1985:27:438-453.

10. Penchansky R, Thomas JW. The concept of access. Med Care. 1981;19:127-140.

11. World Health Organization. WHA58.28 e-Health. En: Fifty-eighth World Health Assembly (WHA58/2005/REC/1). Ginebra, Suiza: World Health Organization; 2005.

12. Boogerd EA, Arts T, Engelen LJ, Van-De-Belt TH. "What is eHealth": time for an update? JMIR Res Protoc. 2015:4:e29.

13. Eysenbach G. What is e-health? J Med Internet Res. 2001;3:e20.

14. Oh H, Rizo C, Enkin M, Jadad A. What is eHealth? A systematic review of published definitions. J Med Internet Res. 2005;7:1-12.

15. Elbert NJ, Van-Os-Medendorp H, Van-Renselaar W, Ekeland AG, Hakkaart-Van-Roijen L, Raat H, et al. Effectiveness and cost-effectiveness of ehealth interventions in somatic diseases: a systematic review of systematic reviews and meta-analyses. J Med Internet Res. 2014; 16:1-23.

16. Flodgren G, Rachas A, Farmer A, Inzitari M, Shepperd S. Interactive telemedicine: effects on professional practice and health care outcomes. Cochrane Database Syst Rev 2015;9:CD002098.

17. Totten AM, Womack DM, Eden KB, McDonagh MS, Griffin JC, Grusing S, et al. Telehealth: mapping the evidence for patient outcomes from systematic reviews. Agency for Healthcare Research and Quality. 2016.

18. Iribarren SJ, Cato K, Falzon L, Stone PW. What is the economic evidence for mHealth? a systematic review of economic evaluations of $\mathrm{mHeal}$ th solutions. PLoS One. 2017;12:e0170581.

19. World Health Organization. eHealth. Report by the Secretariat. Ginebra, Suiza: World Health Organization; 2004.
20. Organización Panamericana de la Salud. Estrategia y plan de acción sobre eSalud. EE. UU.: Organización Panamericana de la Salud; 2011.

21. World Health Organization. Atlas of eHealth country profiles 2015: the use of eHealth in support of universal health coverage. Based on the findings of the third global survey on eHealth 2015. Ginebra, Suiza: World Health Organization; 2016.

22. Lewis T, Synowiec C, Lagomarsino G, Schweitzer J. E-health in low- and middle-income countries: findings from the Center for Health Market Innovations. Bull World Health Organ. 2012;90:332-340.

23. Lau F, Kuziemsky C, Price M, Gardner J. A review on systematic reviews of health information system studies. J Am Med Informatics Assoc. 2010; 17:637-645.

24. Car J, Black AD, Anandan C, Pagliari C, Anandan C, Cresswell K, et al. The impact of eHealth on the quality \& safety of health care: a systematic overview. PLoS One. 2011;8:e1000387.

25. Socio-economic impact of mHealth. An assessment report for Brazil and Mexico. India: PricewaterhouseCoopers Private Limited; 2013.

26. Peters $\mathrm{DH}$, Adam $\mathrm{T}$, Alonge $\mathrm{O}$, Agyepong IA, Tran N. Implementation research: what it is and how to do it. BMJ. 2013;347:f6753.

27. Spiegelman D. Evaluating public health interventions: 1. Examples, definitions, and a personal note. Am J Public Health. 2016;106:70-73.

28. Nilsen $P$. Making sense of implementation theories, models and frameworks. Implement Sci. 2015;10(1):1-13.

29. Tabak RG, Khoong EC, Chambers D, Brownson RC. Bridging research and practice: models for dissemination and implementation research. Am J Prev Med. 2012; 43(3):337-350.

30. World Health Organization. Health information systems development and strengthening. Guidance on needs assessment for national health information development. Ginebra, Ginebra, Suiza: World Health Organization; 2000.

31. World Health Organization. The world health report 2003. Shaping the future. Ginebra, Suiza: World Health Organization; 2003.

32. Heart T, Ben-Assuli O, Shabtai I. A review of PHR, EMR and EHR integration: a more personalized healthcare and public health policy. Health Policy Technol. 2017;6:20-25.

33. Van-De-Wetering R, Batenburg R, Versendaal J, Lederman R, Firth L. A balanced evaluation perspective: picture archiving and communication system impacts on hospital workflow. J Digit Imaging. 2006;19:10-17.

34. Van-Dyk L. A review of telehealth service implementation frameworks. Int J Environ Res Public Health. 2014:11:1279-1298.

35. Scott R, Mars M. Telehealth in the developing world: current status and future prospects. Smart Homecare Technol TeleHealth. 2015;3:25-37.

36. Wootton R, Patil NG, Scott RE, Ho K. Telehealth in the developing world. Inglaterra: The Royal Society of Medicine Press; 2009.

37. World Health Organization. mHealth. New horizons for health through mobile technologies. Ginebra, Suiza: World Health Organization; 2011.

38. Malvey D, Slovensky DJ. mHealth transforming healthcare. EE. UU.: Springer Science; 2015.

39. Wyatt J, Spiegelhalter D. Field trials of medical decision-aids: potential problems and solutions. Proc Annu Symp Comput Appl Med Care. 1991;3-7.

40. Sim I, Gorman P, Greenes RA, Haynes RB, Kaplan B, Lehmann H, et al. Clinical decision support systems for the practice of evidence-based medicine. J Am Med Inf Assoc. 2001;8:527-534.

41. Liu J, Wyatt JC, Altman DG. Decision tools in health care: focus on the problem, not the solution. BMC Med Inform Decis Mak. 2006:6:4.

42. Berlin A, Sorani M, Sim I. A taxonomic description of computer-based clinical decision support systems. J Biomed Inform. 2006;39:656-667.

43. Eysenbach G. Medicine 2.0: social networking, collaboration, participation, apomediation, and openness. J Med Internet Res. 2008;10:e22

44. Riggare S. E-patients hold key to the future of healthcare. BMJ. 2018;360:k846.

45. Raghupathi W, Raghupathi V. Big data analytics in healthcare: promise and potential. Health Inf Sci Syst. 2014;2:3.

46. Dimitrov DV. Medical internet of things and big data in healthcare. Health Inform Res. 2016;22:156-163.

47. Yin $Y$, Zeng $Y$, Chen $X$, Fan $Y$. The internet of things in healthcare: an overview. J Ind Inf Integr. 2016;1:3-13.

48. Clifton DA, Niehaus KE, Charlton P, Colopy GW. Health informatics via machine learning for the clinical management of patients. Yearbook Med Inform. 2015;10:38-43

49. Jha S, Topol EJ. Adapting to artificial intelligence: radiologists and pathologists as information specialists. JAMA. 2016;316:2353-2354.

50. Mirelman A, Rochester L, Maidan I, Del-Din S, Alcock L, Nieuwhof F, et al. Addition of a non-immersive virtual reality component to treadmill training to reduce fall risk in older adults (V-TIME): a randomised controlled trial. Lancet. 2016:388:1170-1182.

51. Martin-Sanchez F, lakovidis I, Nørager S, Maojo V, De-Groen P, VanDer-Lei J, et al. Synergy between medical informatics and bioinformatics: facilitating genomic medicine for future health care. J Biomed Inform. 2004;37:30-42.

52. Radin JM, Topol EJ, Andersen KG, Steinhubl SR, Brendish N, Schiff H, et al. A laboratory in your pocket. Lancet. 2016;388:1875. 
53. Indarte S, Pazos-Gutiérrez P. Estándares e interoperabilidad en salud electrónica: requisitos para una gestión sanitaria efectiva y eficiente. Chile: Comisión Económica para América Latina y el Caribe; 2011.

54. Adebesin F, Kotzé P, Ritz D, Foster R, Van-Greunen D. Method for selecting e-health standards to support interoperability of healthcare information systems. En: IST-Africa 2014 Conference Proceedings. Tanzania: International School of Tanganyika; 2014

55. Fernández-Morales K, Vallejo-Casarín A, McAnally-Salas L. Apropiación tecnológica: una visión desde los modelos y las teorías que la explican. Perspect Educ. 2015;54:109-125.

56. Isaac $\mathrm{H}$, Besseyre-Des-Horts $\mathrm{CH}$, Leclercq A. Adoption and appropriation: towards a new theoretical framework, an exploratory research on mobile technologies in French companies. Systèmes d'Information Manag. 2006;11:9-50.
57. Korpelainen K. Theories of ICT system implementation and adoption: a critical review. Finlandia: School of Science and Technology/Aalto University; 2011

58. Delone WH, McLean E. The DeLone and McLean model of information systems success: a ten-year update. J Manag Inf Syst. 2003:19:9-30.

59. Cooper RB, Zmud RW. Information technology implementation research: a technological diffusion approach. Manag Sci. 1990;36:123-139.

60. Pinnock $H$, Barwick M, Carpenter CR, Eldridge S, Grandes G, Griffiths CJ, et al. Standards for Reporting Implementation Studies (StaRI) Statement. BMJ. 2017;356:i6795.

61. Wilson PM, Sales A, Wensing M, Aarons GA, Flottorp S, Glidewell L, et al. Enhancing the reporting of implementation research. Implement Sci. $2017 ; 12: 13$ 